\title{
Transcription units as RNA processing units
}

\author{
Karla M. Neugebauer ${ }^{1}$ and Mark B. Roth
}

Fred Hutchinson Cancer Research Center, Division of Basic Sciences, Seattle, Washington 98109 USA

Several observations made over the past year have forged strong molecular links between transcription by RN A polymerase II (Pol II) and pre-mRNA processing. The key findings support the view that the carboxy-terminal domain (CTD) of the large subunit of RNA polymerase II binds directly to protein factors essential for RNA processing. In some cases, there is a clear suggestion that the factors only bind when the polymerase is in the act of transcriptional elongation. As a result, it is now possible to discuss the transcription unit as an RNA processing unit in which the action of RNA Pol II itself brings essential el ements of each of these processing steps to the nascent pre-mRN A substrate. Within this RN A processing unit, capping, splicing, and polyadenylation can also regulate one another.

As pre-mRN $A$ is synthesized, it undergoes a number of modifications that determine the protein encoded as well as the stability and translatablity of the mRNA. First, the $5^{\prime}$ end of the premRNA is modified by capping, in which the terminal phosphate is cleaved and a GMP nucleotide is linked by a $5^{\prime}-5^{\prime}$ triphosphate bridge to produce $G$ pppN. Subsequently, the $G$ is methylated at the $N 7$ position, and this $m^{7} G$ constitutes the cap (Shatkin 1976). The $m^{7} G$ cap is added shortly after transcriptional initiation within a narrow window of nucleotides ( +20 to +40$)$, indicating that the reaction is rapid and efficient (Salditt-Georgieff et al. 1980; Coppola et al. 1983; Jove and Manley 1984; Rasmussen and Lis 1993). The observation that cap-binding complex (CBC) associates with premRNA early in RNA synthesis provides additional evidence that capping can occur during splicing (Visa et al. 1996b). The two subunits of CBC, CBP80 and CBP20, are bound to the cap throughout the RNA's lifetime in the nucleus and have important roles in the identification of the first exon during pre-mRNA transcription, $3^{\prime}$-end formation, and nuclear export (for review, see Lewis and Izuarralde 1997). The CBC dissociates from the cap in the cytoplasm, where the cap is subsequently bound by the translational regulator el F-4E (Lewis and Izuarralde 1997).

PremRNA splicing is a two-step transesterification reaction that removes intron sequences and ligates exon sequences together. This reaction requires the splicing

\section{${ }^{1}$ Corresponding author.}

E-MAIL kneugeba@fred.fhcrc.org, FAX (206) 667-6503. small nuclear ribonucleoprotein (snRN Ps) as well as a number of non-snRNP splicing factors that assemble with the premRNA to form a multiprotein complex known as the spliceosome (M oore et al. 1993). Cytological studies revealed that complexes begin to associate with proximal splice sites before distal splice sites are synthesized, and that intron removal often occurs while el ongating transcripts are still attached to the DN A (Osheim et al. 1985; Beyer and Osheim 1988). The latter observation provided the first convincing evidence that splicing can occur during transcription. Cotranscriptional splicing has subsequently been confirmed in a variety of systems and has been shown to precede polyadenylation (LeM aire and Thummel 1990; Zachar et al. 1993; Bauren and Wieslander 1994; Zhang et al. 1994; Bauren et al. 1996).

Polyadenylation of the $3^{\prime}$ end of the RNA is achieved by first cleaving the pre-mRN A downstream of a consensus sequence, AAUAAA, which is the binding site of cleavage and polyadenylation specificity factor (CPSF). Cleavage stimulation factor (CStF) binds a GU-rich sequence downstream of AAUAAA, and cleavage factors I and II are both required for the cleavage event. Subsequently, the new poly $(A)$ tail is synthesized in the nucleus and/or the cytoplasm by poly(A) polymerases (M anley 1995). Because both AAUAAA and GU-rich sequences are also required for termination of transcription by RN A Pol II (Whitel aw and Proudfoot 1986; Logan et al. 1987; Connel ly and $M$ anl ey 1988), polyadenylation cleavage is likely to be integrated with the process of transcription.

$N$ either capping, splicing, nor polyadenylation occurs efficiently when transcripts are synthesized by RN A Pol I or Pol III (Smale and Tjian 1985; Sisodia et al. 1987; Gunnery and Matthews 1995), suggesting that there is something special about RNA Pol II that permits the integration of these processes. Corden (1990) proposed that the unique feature of RN A Pol II would prove to be the CTD, a domain comprised of a heptad repeat el ement (YSPTSPS in mouse) conserved throughout evolution but varying in the number of repeats from 26 in yeast to 52 in mouse. The CTD is dynamic with respect to its phosphorylation state during transcription. During preinitiation complex formation and initiation, the CTD is hypophosphorylated, and this form of the polymerase is known as Pol Ila (Dahmus 1996). The polymerase often pauses after synthesizing only $20-30$ nucl eotides, and as 
it passes into elongation mode, the CTD is hyperphosphorylated by TFIIH to produce Pol Ilo (O'Brien et al. 1994; Dahmus 1996). This reaction occurs precisely when capping occurs (Rasmussen and Lis 1993).

Two studies reveal the logic behind the correlation between capping and CTD phosphorylation: The capping enzymes themselves associate with the CTD but only when the CTD is phosphorylated (Cho et al .; M cCracken et al.; both this issue). In higher eukaryotes, the enzymatic activities for capping resi de on one protein for the triphosphatase and guanylyltransferase activities in addition to the methyltransferase (Shuman 1995). In Saccharomyces cerevisiae, two separable enzymes, guanyltransferase (Cegl) and triphosphatase, exist as subunits of the capping enzyme, and the methyltransferase (Abd1) has al so been identified. M cCracken and colleagues (this issue) examine capping in human cells whose only active Pol II has a truncated CTD (5 heptad repeats instead of 52) and find that the CTD truncation leads to a fivefold decrease in thelevel of capping of several test RN As. The observation that guanylyltransferase activity is eluted from a CTD-GST affinity column, but only if the CTD has been first phosphorylated by the kinase subunit of TFIIH, cdk 7-cycH kinase, is consistent with a direct molecular connection between transcription and capping (McCracken et al., this issue). This capping enzyme cDNA was cloned from mouse, and the in vitro translated protein product was shown to bind specifically to the phosphorylated CTD resin. Like the mouse and human counterpart, yeast Cegl as well as the methyltransferase Abdl bind the CTD in a phosphorylation-dependent manner (Cho et al.; McCracken et al.; both this issue). There is some disagreement as to whether each capping component can bind the CTD al one. M cCracken et al. (this issue) show that each recombinant protein can bind independently to the phosphorylated CTD column, whereas Cho et al. (this issue) find that bacterially expressed Cegl cannot. However, it is clear from both studies that the native capping enzymes bind, and Cho et al . make the additional point that Cegl is not detectable in association with Pol II transcription factors or Pol II holoenzyme until the CTD has been phosphorylated by TFIIH.

The association of capping activities with RN A Pol II explains how this modification is specifical ly targeted to Pol II transcripts, as there are no determinants on the nascent RN A to specify capping. It is a strategy taken by a CTD-less RNA polymerase, that of vaccinia virus, which binds to the capping enzyme by an independent mechanism (Hagler and Shuman 1992). The fact that Pol I and Pol III transcripts are not capped can now be attributed to the lack of the CTD in those polymerases. The requirement that the CTD be phosphorylated prior to capping enzyme binding may be to prevent capping of RN As that are not destined for el ongation. At this time, it is not known whether the $C B C$ also associates with the polymerase, but this might facilitate its rapid binding to the cap (Visa et al. 1996b).

The work reported in this issue falls on the heels of evidence that pre-mRNA splicing and polyadenylation factors associate with the CTD (for review, see Steinmetz 1997). Importantly, the truncated CTD form of Pol II described above, was insufficient for premRN A splicing, polyadenylation, and transcriptional termination; the effects on polyadenylation and termination were shown to be independent of the effects on splicing (M cCracken et al. 1997a). The polyadenylation factors CstF and CPSF were shown to bind TAF (TATA-binding protein-assoi ated factor) components of TFIID as well as the CTD (Dantonè et al. 1997; M CCracken et al. 1997a). In other studies that address splicing, Du and Warren (1997) showed that overexpression of the CTD in HeLa cells interfered with splicing, and Yuryev et al. (1996) found that Pol II depletion from HeLa nuclear extract or the addition of CTD peptides could inhibit in vitro splicing. A possible explanation for these data is provided by the observations that splicing snRNPs and members of the SR protein family of non-snRN P pre-mRN A splicing factors associate with the hyperphosphorylated form of Pol II (Chabot et al. 1995; Vincent et al. 1996; M ortillaro et al. 1996; Kim et al. 1997). In addition, Yuryev et al . (1996) detected three as yet uncharacterized proteins associated with the hyperphosphorylated form of Pol II. These proteins are related to SR proteins through their argininerich domains but cl early are not canonical SR proteins. It will be of interest to learn how these three proteins function in RNA processing. A more significant challenge will be the development of cotranscriptional splicing systems, which will allow us to fully appreciate the significance of splicing factor association with the CTD on the one hand and permit a mechanistic description of transcription and splicing (as we have for transcription and capping) on the other.

An important question for the model (Fig. 1 ) is whether RNA Pol II is constitutively associated with processing factors in a multifunctional "holo-particle" or whether complexes are formed in a more dynamic way in which the processing factors associate only once polymerase is el ongating. The work on capping and polyadenylation clearly favors the preferential association of factors with the elongating polymerase. Both groups studying the capping enzymes find that these molecules only have affinity for the hyperphosphorylated CTD (Cho et al.; M cCracken et al.; both this issue). Interestingly, the polyadenylation factors CPSF and CstF have affinity for both phosphorylation forms of the CTD (M CCracken et al. 1997a). However, a recent study shows that CPSF is brought to the transcription unit by TFIID, CPSF binding is only transferred to the CTD after elongation begins, and TFIID is left behind at the promoter (Dantonel et al. 1997). Thus, in the case of CPSF, binding to the CTD may not be determined solely by phosphorylation but also by the sequestration of the factor(s) in other functional complexes. Importantly, the association of this factor with TFIID al so ensures CPSF targeting to RNA Pol II transcripts.

How do factors associate with the CTD? Greenleaf (1993) first proposed that argininerich domains of splicing factors would interact with the phosphorylated CTD through electrostatic interactions. M any metazoan splic- 

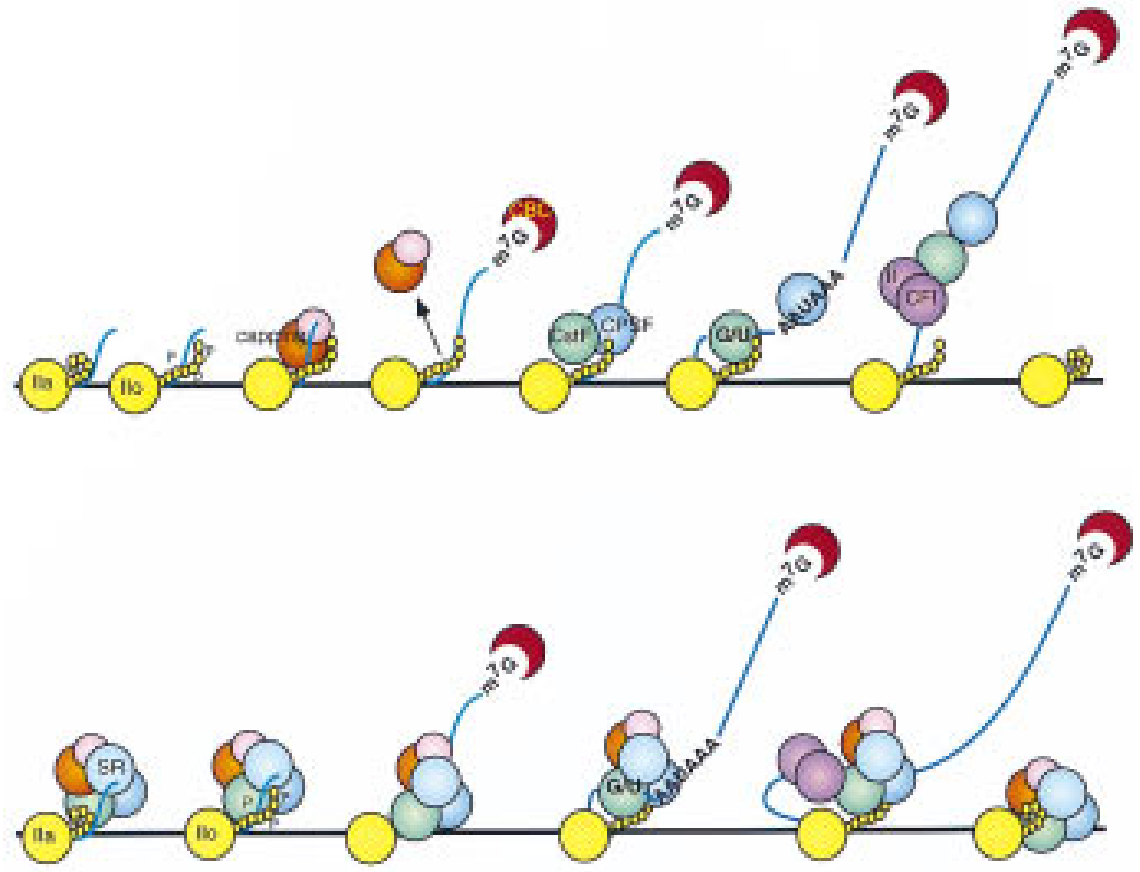

Figure 1. Transcription of an intronless gene. (Top) The dynamic assembly of factors on the CTD as well as the RNA substrate. (Left to right) As RN A polymerase II begins elongation, the CTD is hyperphosphorylated and capping enzymes associate. The nascent RNA is capped and capping enzymes diffuse away. Subsequently, CPSF and CstF associate with the CTD and bind their target RNA sequences upon their synthesis. The binding of these factors leads to recruitment of the cleavage factors, which carry out polyadenylation cleavage. Transcription is terminated, and the naked polymerase awaits reentry into the cycle. (Bottom) A holoparticle of the polymerase associated with all of the possible factors needed for processing, including SR proteins even though this gene has no introns. As the RNA is synthesized, it moves through the particle for modification. When additional factors are needed (e.g., the cleavage factors), they add to the complex at the polymerase. ing factors, including the SR proteins, contain such alternating-argi nine domains comprised al most enti rely of argi nine alternating with gl utamate, aspartate, and phosphoserine (N eugebauer et al . 1995). However, the overal I positive charge of these domains cannot be assumed, as many of the intervening amino acids (aspartate, glutamate, and phosphoserine) are negatively charged. Although splicing factor candidates observed to associate with the CTD were alternating-arginine proteins (Yuryev et al. 1996), the same study showed that the protein domains apparently responsible for CTD binding were distinct from the alternating-arginine domains. Thus, alternating-arginine proteins, including the SR proteins, have a tendency to associate with the CTD, but this may not be due to the alternating-arginine domain itself. However, none of the capping or polyadenylation factors studied thus far have arginine-rich domains typical of splicing factors (Manley 1995; McCracken et al., this issue). It will be important to determine which regions of these latter factors are required for CTD binding.

The results of M cCracken et al. (1997a and this issue) show that five heptad repeats of the CTD are sufficient for transcription but not for RN A processing. One wonders whether the RN A processing functions have similar minimal requirements for CTD heptads and whether this requirement can be understood in terms of the stoichiometry of factor association with RNA Pol II. Interestingly, truncation mutants of the CTD reveal that organisms can survive with as many as one-half of the CTD deleted (Allison et al. 1988; Bartolomei et al. 1988). Zehring et al. (1988) found that al though a truncation of the CTD in Drosophila Pol II from 42 to 20 heptad repeats was lethal in the homozygote, this purified truncated polymerase was fully active for transcription in vitro on a variety of promoters. This suggests that the lethality may have been due to RN A processing phenotypes rather than a block of transcription. N ow that the connection between the CTD and RNA processing has been made, perhaps it will be possible to re-examine the molecular phenotypes of these truncation mutants.

The possibility that factors associate in a dynamic way with the CTD of the elongating polymerase is attractive with respect to splicing in particular, because the nascent RN A itself could play a role in the binding specificity of the processing factors. Though nearly every mRNA is capped and polyadenylated, not every transcript is spliced. In yeast, only 235 genes of at least 5885 are spliced (Goffeau et al. 1996), making the association of snRN Ps with every transcription unit a highly inefficient prospect. In contrast, mRN A-type splicing can al so occur when RNA is transcribed by RNA Pol III, as in the case of U 6 snRN A synthesis (Koehrer et al. 1990; Tani and Oshima 1991). Consistent with a role for the RNA in splicing factor recruitment, Huang and Spector (1996) found that splicing factor association with transfected expression constructs was dependent on the presence of an intron. Transcripts containing many exons and introns may "grab" splicing factors from the CTD for spliceosome assembly (Fig. 2). In this scenario, the empty CTD must then be reloaded to supply the next splice site with factors. Overall, it would make sense that factors could assemble with the CTD during the process of transcription and processing, in the manner suggested by the term "Ioading site" (Corden 1990). In this model, the CTD would stabilize factor binding to an RN A sequence for which the factor al ready has some specificity.

The fact that splicing in metazoans is regulated, producing alternative splicing, raises questions about how particular splicing factors associate with various transcription units. The SR proteins have been shown to 
Figure 2. Transcription and splicing of an RNA containing multiple introns and exons. An elongating RN A is al ready capped and the CTD is bound to splicing factors, including SR proteins, other non-snRNP splicing factors (e.g., U2AF), and snRN Ps that recognize exons and splice sites. As the first exon is synthesized, factors recognizing the first $5^{\prime}$ splice site of the first intron are bound to the RN A. Subsequently, other factors bind to the $3^{\prime}$ splice site ( $3^{\prime} \mathrm{SS}$ ) of that intron, and SR proteins associate with exon 2. A spliceosome is assembled. This depletes the the polymerase of the splicing factors it initially carried, and these splicing factors are replenished from soluble, nucleoplasmic pools. The cycle is repeated, depending on the number of introns and exons in the gene.

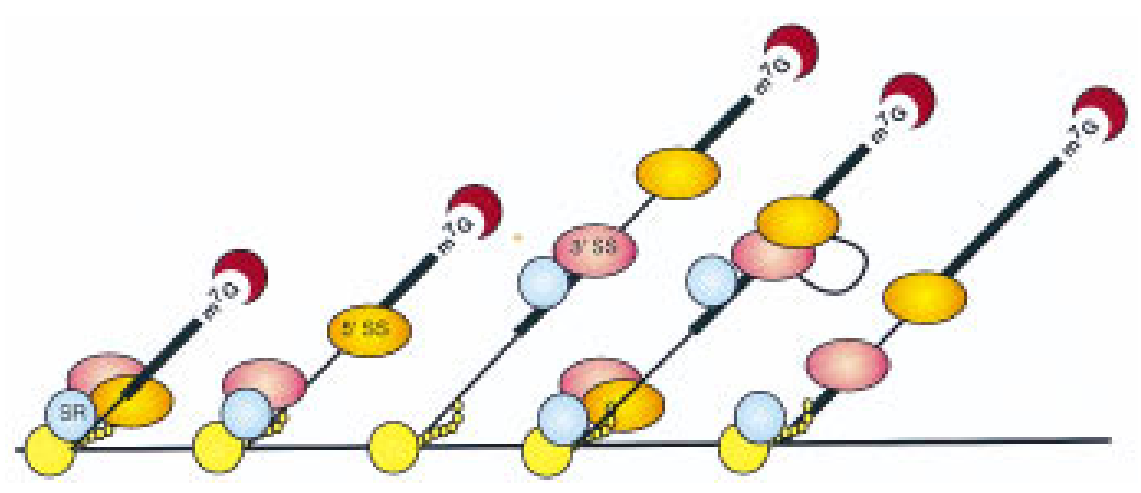

have distinct functions in determining exon usage (Fu 1993; Zahler et al. 1993; Caceres et al. 1994), and current evidence indicates that this is due, at least in part, to differences among the SR proteins in RNA-binding specificity (e.g., see M anl ey and Tacke 1996). The observation that particular SR proteins are heterogeneously distributed at active sites of transcription suggests that distinct factors may be specifically recruited to nascent transcripts (N eugebauer and Roth 1997). Furthermore, there are seemingly too many SnRNP and non-snRNP splicing factors in the metazoan cell nucl eus for them al I to associate with each CTD all of the time. The canonical SR proteins bel ong to a larger family of $\sim 25$ alternating-arginine proteins, including the essential splicing factors $U 2 A F^{65}$ and $U 2 A F^{35}$ (N eugebauer et al. 1995). Furthermore, the spliceosome is a dynamic association of proteins and RNAs that evolves from $E$ to $A$ to $C$ complex during the spliceosome cycle; 60 polypeptides are present in C complex alone (Moore et al. 1993; Gozani et al. 1994). Certainly, the greater number of factors required for regulated splicing in metazoans could hel $p$ explain the correlation between the length of the CTD and the complexity of the organism (Corden 1990). In the future, it will be important to distinguish between a model in which all of the components of the spliceosome are brought to the substrate by the CTD from a model in which only sel ected splicing factors bind to the CTD and promote the assembly of the spliceosome from mostly nucleoplasmic components.

It is possible that the idea of the RNA participating in determining the specificity of factor binding can be generalized to other processes, such as polyadenylation and transcriptional termination. Both CPSF and CstF have bindingsites on the nascent RNA. The CTD may play an important role in stabilizing these sequence-dependent interactions, however, as the RNA sequences bound (AAUAAA and GU-rich tracts) are likely to be present in Pol I and Pol III transcripts that are not polyadenylated. Conversely, transcription of rDN A by Pol II yields a prerRNA that is processed appropriately to large rRNAs, demonstrating that the function of the CTD in processing is not dominant over other processing signals ( $N$ ogi et al. 1991). Moreover, the dual binding site model allows for the possi bility that CPSF and/or CstF binding to the nascent RN A signals termination to the polymerase through the CTD. Alternatively, a distinct Pol II termination factor may be recruited to the transcription unit by the polyadenylation complex with or without the aid of the CTD.

The synchronization of transcription and RNA processing events surely has significance beyond the targeting of RNA modifications to Pol II transcription units. For many years now it has been appreciated that capping, splicing, and polyadenylation are interrelated processes, suggesting that some of the effects detectable by genetic manipulation of these close-knit processes, such as inhibition of pre-mRN A splicing, may actual ly be indirect effects of having disturbed the overall processing pathway. This may be understood by consi dering that the cap defines the $5^{\prime}$ end of the premRNA - the first exonwhereas the poly(A) site defines the $3^{\prime}$ end-the last exon. Pre-mRN A splicing is blocked when capping activity is inhibited genetically in yeast (Fresco and Buratowski 1996) or when substrate premRNAs lacking a cap are spliced in vitro (Ohno et al. 1987). This suggests that the cap is part of a multistep mechanism for identifying the first exon in the pre-mRNA. Recognition of the cap by the CBC has been shown to stimulate the formation of the earliest spliceosomal complex, complex E (Colot et al. 1996; Lewis et al. 1996). Berget and colleagues found that the presence of an intron upstream of a pol yadenylation signal sti mulated cleavage ( $\mathrm{N}$ i wa et al . 1990) and, conversely, that wild-type polyadenylation signals are required for efficient splicing of the last exon (N iwa and Berget 1991). This interesting interaction between polyadenylation and splicing is important, because many alternative splicing events involve a choice of alternative terminal exons. Recently Lou et al. (1996) have characterized an intronic enhancer of polyadenylation cleavage in the calcitonin/CGRP (cal citonin gene- 
related peptide) gene that results in the alternative processing of the premRNA. Interestingly, this intronic enhancer associates with the U 1 SnRNP, SR proteins, and another splicing regulator, PTB (polypyrimidine tractbinding protein) (Lou et al. 1996). Finally, the cap even appears to affect polyadenylation. Several studies have found that efficient polyadenylation cleavage requires the cap structure (Gilmartin et al. 1988; Cooke and Alwine 1996), and that this effect is al so mediated by the CBC (Flaherty et al. 1997). In yeast, however, inhibition of capping has no detectable effect on polyadenylation (Fresco and Buratowski 1996). That polyadenylation signals differ between yeast and metazoans perhaps is another difference reflecting the reduced complexity of the yeast transcription unit.

One nuclear function that may be connected to transcription-but has not been yet-is nuclear export. Many Pol II transcripts are destined for the cytoplasm, and they are generally escorted to the nuclear pore by protein factors in a particle, the messenger RN P (mRNP; Daneholt 1997; Ullman et al. 1997). It is known that the cap promotes RNA export, and this effect is probably mediated by the binding of CBC ( $\mathrm{Hamm}$ and Mattaj 1990; Izuarralde et al. 1995; Visa et al. 1996b). Interestingly, intron-containing RNAs seem to be specifically retained in the nucleus (Hamm and Mattaj 1990). Some factors that have been observed in association with RNAs in the process of export include the CBC, heterogenous nuclear RN Ps (hnRN Ps), and SR proteins (PiñolRoma and Dreyfuss 1992; Visa et al. 1996a; Visa et al. 1996b; Daneholt 1997). As discussed above, association of some of these factors with RN A is perhaps guided by the polymerase itself, indirectly connecting export with transcription. It will be of interest to learn whether hnRNP protein association with RNA is in any way facilitated by the CTD. An additional possibility is that other export factors bearing nuclear export signals (NESs; for review, see Ullman et al. 1997) may also associate with the CTD, such that the local concentration of the export factors is highest where the MRNP is being assembled. In particular, do recently identified components of the nuclear export pathway, such as exportin 1, have any affinity for RNA Pol II that synthesizes the RNAs for transport?

M ost of our concern thus far has been directed toward understanding how RNA processing follows from the initiating event-transcription. If RNA processing factors bind to the polymerase, it is likely that processing can influence transcription, just as we now know the reverse is true. To what extent do processing factors affect the activity of the polymerase? Several studies in nematodes and mice have shown a dependence on the presence of introns for gene expression driven by a variety of promoters (Brinster et al. 1988; Okkema et al. 1993). In particular, transgenic mice harboring introncontaining or intron-less genes behind natural promoters show intron-dependent expression of those genes (Brinster et al. 1988). Moreover, the change in RNA abundance exactly parallels measured changes in transcriptional rates for the intron-containing constructs. This suggests a positive feedback mechanism between RN A processing, in this case splicing, and transcriptional activity. In this scenario, the presence of an intron might stimulate the accumulation of splicing factors that bind the CTD.

In the last year, our concept of the transcription unit has changed from that of a place in which RN A is synthesized and processed very rapidly through a series of independent biochemical events to one in which RNA synthesis is coordinated with processing. If elongating RNA Pol II can act to increase the local concentrations of processing factors specific for these transcripts, then nuclear organization is, at least in part, determined by gene activity. It suggests that the transcription unit, once fired, is a self-assembling functional unit. This concept is very different from models put forth in the last decade in which different functions in mRN A biogenesis are proposed to be compartmentalized into distinct domains within the nucleoplasm (e.g., see Moen et al. 1995; de Jong et al. 1996). Examination of transcription units in cytological preparations from amphibians and insects has revealed that processing factors are highly concentrated at active sites of transcription (Gall 1991; Bauren et al. 1996; Daneholt 1997). However, we have been reluctant to extrapolate these observations to all nuclei (M attaj 1994). Recent progress in high-resolution light microscopy, immunocytochemical methods, and in situ hybridization techniques indicate that we can examine these transcription units in mammalian interphase nuclei as well. Already, we have seen that active sites of RN A Pol II transcription are distributed throught the nucleoplasm (Wansink et al. 1993) and that they are the sites of high concentrations of RNA Pol II, SR proteins, and CstF (Iborra et al. 1996; Schul et al. 1996; N eugebauer and Roth 1997; Zeng et al. 1997). This cell biological approach is bound to complement the biochemical and genetic approaches already ongoing to understand the rules and regulations of transcription unit assembly.

\section{Acknowledgments}

We thank M. Groudine, I. M attaj, R. Reeder, B. Moorefield, and S. Hahn for stimulating conversations and comments on the manuscript. K.M.N. was a fellow of the Alexander von Humboldt-Stiftung.

\section{References}

Allison, L.A., J.K.-C. Wong, V.D. Fitzpatrick, M. M oyle, and C.J. Ingles. 1988. The $\mathrm{C}$-terminal domain of the largest subunit of RNA polymerase II of Saccharomyces cerevisiae, Drosophila melanogaster, and mammals: A conserved structure with an essential function. Mol. Cell. Biol. 8: 321-329.

Bartolomei, M.S., N.F. Halden, C.R. Cullen, and J.L. Corden. 1988. Genetic analysis of the repetitive carboxyl-terminal domain of the largest subunit of mouse RN A polymerase II. Mol. Cell. Biol. 8: 33-339.

Bauren, G. and L. Wieslander. 1994. Splicing of Bal biani Ring 1 gene pre-mRNA occurs simultaneously with transcription. Cell 76: 183-192.

Bauren, G., W.-Q. Jiang, K. Bernholm, F. Gu, and L. Wieslander. 
1996. Demonstration of a dynamic, transcription-dependent organization of pre-mRNA splicing factors in polytene nuclei. J. Cell Biol. 133: 929-941.

Beyer, A.L. and Y.N. Osheim. 1988. Splice site selection, rate of splicing, and alternative splicing on nascent transcripts. Genes \& Dev. 2: 754-765.

Brinster, R.L., J.M. Allen, R.R. Behringer, R.E. Gelinas, and R.D. Palmiter. 1988. Introns increase transcriptional efficiency in transgenic mice. Proc. Natl. Acad. Sci. 85: 836-840.

Caceres, J.F., S. Stamm, D.M. Helfman, and A.R. Krainer. 1994. Regulation of alternative splicing in vivo by over expression of antagonistic splicing factors. Science 265: 1706-1709.

Chabot, B., S. Bisotto, and M. Vincent. 1995. The nuclear matrix phosphoprotein p255 associates with splicing complexes as part of the U 4/U 6.U 5 tri-snRN P particle. Nucleic Acids Res. 23: 3206-3213.

Cho, E.-J., T. Takagi, C.R. Moore, and S. Buratowski. 1997. mRNA capping enzyme is recruited to the transcription complex by phosphorylation of the RNA polymerase II carboxy-terminal domain. Genes \& Dev. (this issue).

Colot, H.V., F. Stutz, and M. Rosbash. 1996. The yeast splicing factor Mud13p is a commitment complex component and corresponds to CBP20, the small subunit of the nuclear capbinding complex. Genes \& Dev. 10: 1699-1708.

Connelly, S. and J.L. Manley. 1988. A functional mRNA polyadenylation signal is required for transcription termination by RN A polymerase II. Genes \& Dev. 2: 440-452.

Cooke, C. and J. Alwine. 1996. The cap and the $3^{\prime}$ splice site similarly affect polyadenylation efficiency. Mol. Cell. Biol. 16: $2579-2584$.

Coppola, J.A., A.S. Field, and D.S. Luse. 1983. Promoter-proximal pausing by RNA polymerase II in vitro: transcripts shorter than 20 nucleoti des are not capped. Proc. Natl. Acad. Sci. 80: 1251-1255.

Corden, J.L. 1990. Tails of RNA polymerase II. Trends Biochem. Sci. 15: 383-387.

Dahmus, M.E. 1996. Reversible phosphorylation of the C-terminal domain of RNA polymerase II. J. Biol. Chem. 271: 19009-19012.

Daneholt, B. 1997. A look at messenger RN P moving through the nuclear pore. Cell 88: 585-588.

Dantonel, J.-C., K.G.K. M urthy, J.L. Manley, and L. Tora. 1997. Transcription factor TFIID recruits factor CPSF for formation of 3' end of mRNA. Nature 389: 399-402.

de Jong, L., M.A. Grande, K.A. Mattern, W. Schul, and R. van Driel. 1996. Nuclear domains involved in RNA synthesis, RNA processing and replication. Crit. Rev. Euk. Gene Exp. 6: 215-246.

Du, L. and S.L. Warren. 1997. A functional interaction between the carboxy-terminal domain of RNA polymerase II and pre mRN A splicing. J. Cell Biol. 136: 5-18.

Flaherty, S.M., P. Fortes, E. Izaurral de, I.W. Mattaj, and G. Gilmartin. 1997. Participation of the nuclear cap binding complex in pre-mRNA $3^{\prime}$ processing. Proc. Natl. Acad. Sci. 94: 11893-11898.

Fresco, L.D. and S. Buratowski. 1996. Conditional mutants of the yeast mRNA capping enzyme show that the cap enhances, but is not required for, mRN A splicing. RNA 2: 584596.

Fu, X.-D. 1993. Specific commitment of different pre-mRN As to splicing by single SR proteins. Nature 365: 82-85.

Gall, J. 1991. Spliceosomes and snurposomes. Science 252: 1499-1500.

Gilmartin, G.M., M.A. McDevitt, and J.R. Nevins. 1988. Multiple factors are required for specific RNA cleavage at a poly(A) addition site. Genes \& Dev. 2: 578-587.
Goffeau, A., B.G. Barrell, H. Bussey, R.W. Davis, B. Dujon, H. Feldmann, F. Galibert, J.D. Hohei sel, C. Jacq, M. Johnston, E.J. Louis, H.W. M ewes, Y. M urakami, P. Phillipsen, H. Terrelin, and S.G. Oliver. 1996. Life with 6000 genes. Science 274: 546-567.

Gozani, O., J.G. Patton, and R. Reed. 1994. A novel set of spliceosome-associated proteins and the essential splicing factor PSF bind stably to pre-mRN A prior to catalytic step II of the splicing reaction. EMBO J. 13: 3356-3367.

Greenleaf, A. 1993. Positive patches and negative noodles: Linking RNA processing to transcription? Trends Biochem. Sci. 18: 117-119.

Gunnery, S. and M.B. Matthews. 1995. Functional mRNA can be generated by RNA polymerase III. Mol. Cell. Biol. 15: 3597-3607.

Hagler, J. and S. Shuman. 1992. A freeze-frame view of eukaryotic transcription during el ongation and capping of nascent mRN A. Science 255: 983-986.

Hamm, J. and I. Mattaj. 1990. Monomethylated cap structures facilitate RN A export from the nucleus. Cell 63: 109-118.

Huang, S. and D.L. Spector. 1996. Intron-dependent recruitment of pre-mRNA splicing factors to sites of transcription. J. Cell Biol. 133: 719-732.

Iborra, F.J., A. Pombo, D.A. Jackson, and P.R. Cook. 1996. Active RNA polymerases are localized within discrete transcription "factories" in human nuclei. J. Cell Sci. 109: 14271436.

Izuarral de, E., J. Lewis, C. Gamberi, A. Jarmolowski, C. M cGuigan, and I. Mattaj. 1995. A cap-binding protein complex mediating UsnRN A export. Nature 376: 709-712.

Jove, R. and J.L. Manley. 1984. In vitro transcription from the adenovirus 2 major late promoter utilizing templates truncated at promoter-proximal sites. J. Biol. Chem. 259: 85138521.

Kim, E., L. Du, D.B. Bregman, and S.L. Warren. 1997. Splicing factors associate with hyperphosphorylated RNA polymerase II in the absence of pre-mRN A. J. Cell Biol. 136: 19-28.

Koehrer, K., K. Vogel, and H. Domdey. 1990. A yeast tRN A precursor containing a pre-mRNA intron is spliced via the pre-mRNA splicing mechanism. EMBO J. 9: 705-709.

LeM aire, M .F. and C.S. Thummel. 1990. Splicing precedes polyadenylation during Drosophila E74A transcription. Mol. Cell. Biol. 10: 6059-6063.

Lewis, J.D. and E. Izuarral de. 1997. The role of the cap structure in RNA processing and nuclear export. Eur. J. Biochem. 247: 461-469.

Lewis, J.D., E. Izaurral de, A. Jarmolowski, C. McGuigan, and I.W. Mattaj. 1996. A nuclear cap-binding complex facilitates association of U 1snRN P with the cap-proximal 5' splice site. Genes \& Dev. 10: 1683-1698.

Logan, J., E. Fal ck-Pedersen, J.E. Darnell, and T. Shenk. 1987. A poly(A) addition site and a downstream termination region are required for efficient cessation of transcription by RNA polymerase $\mathrm{II}$ in the mouse $\mathrm{b}^{\text {maj }}$-globin gene. Proc. Natl. Acad. Sci. 84: 8306-8310.

Lou, H., R.F. Gagel, and S.M. Berget. 1996. An intron enhancer recognized by splicing factors activates polyadenylation. Genes \& Dev. 10: 208-219.

Manley, J.L. 1995. A complex protein assembly catalyzes polyadenylation of mRNA precursors. Curr. Opin. Genet. Dev. 5: 222-228.

Manley, J.L. and R. Tacke. 1996. SR proteins and splicing control. Genes \& Dev. 10: 1569-1579.

Mattaj, I. 1994. Splicing in space. Nature 372: 727-728.

McCracken, S., N. Fong, K. Yankulov, S. Ballantyne, G. Pan, J. Greenblatt, S.D. Patterson, M. Wiskens, and D.L. Bentley. 
1997a. The C-terminal domain of RNA polymerase II couples mRNA processing to transcription. Nature 385: 357-361.

M cCracken, S., N . Fong, E. Rosonina, K. Yankulov, G. Brothers, D. Siderovski, A. Hessel, S. Foster, Amgen EST Program, S. Shuman, and D.L. Bentley. 1997b. 5' capping enzymes are targeted to pre-mRN A by binding to the phosphorylated carboxy-terminal domain of RNA polymerase II. Genes \& Dev. (this issue).

M oen, P.T., K.P. Smith, and J.B. Lawrence. 1995. Compartmentalization of specific pre-mRNA metabolism: An emerging view. Hum. Mol. Genet. 4: 1779-1789.

Moore, M.J., C.C. Query, and P.A. Sharp. 1993. Splicing of precursors to mRN A by the spliceosome. In The RNA world (ed. R.F. Gesteland and J.F. Atkins), pp. 303-357. Cold Spring Harbor Laboratory Press, Cold Spring Harbor, NY.

M ortillaro, M.J., B.J. Blencowe, X. Wei, H. N akayasu, L. Du, S.L. Warren, P.A. Sharp, and R. Berezney. 1996. A hyperphosphorylated form of the large subunit of RN A polymerase II is associated with splicing complexes and the nuclear matrix. Proc. Natl. Acad. Sci. 93: 8253-8257.

Neugebauer, K.M. and M.B. Roth. 1997. Distribution of pre mRN A splicing factors at sites of RNA polymerase II transcription. Genes \& Dev. 11: 1148-1159.

N eugebauer, K.M., J.A. Stolk, and M .B. Roth. 1995. A conserved epitope on a subset of SR proteins defines a larger family of pre-mRN A splicing factors. J. Cell Biol. 129: 899-908.

Niwa, M., S.D. Rose, and S.M. Berget. 1990. In vitro polyadenylation is stimulated by the presence of an upstream intron. Genes \& Dev. 4: 1552-1559.

Niwa, M. and S. Berget. 1991. Mutation of the AAUAAA polyadenylation signal depresses in vitro splicing of proximal but not distal introns. Genes \& Dev. 5: 2086-2095.

Nogi, Y., R. Yano, and M. Nomura. 1991. Synthesis of large rRN As by RN A polymerase II in mutants of Saccharomyces cerevisiae defective in RN A polymerase I. Proc. Natl. Acad. Sci. 88: 3962-3966.

O'Brien, T., S. Hardin, A. Greenleaf, and J.T. Lis. 1994. Phosphorylation of RNA polymerase II C-terminal domain and transcriptional elongation. Nature 370: 75-77.

Ohno, M., H. Sakamoto, and Y. Shimura. 1987. Preferential excision of the $5^{\prime}$ proximal intron from mRN A precursors with two introns as mediated by the cap structure. Proc. Natl. Acad. Sci. 84: 5187-5191.

Okkema, P.G., S.W. Harrison, V. Plunger, A. Aryana, and A. Fire. 1993. Sequence requirements for myosin gene expression and regulation in Caenorhabditis elegans. Genetics 135: 385-404.

Osheim, Y.N., O.L. Miller, Jr., and A.L. Beyer. 1985. RN P particles at splice junction sequences on Drosophila chorion transcripts. Cell 43: 143-151.

Piñol-Roma, S. and G. Dreyfuss. 1992. Shuttling of pre-mRN A binding proteins between nucleus and cytoplasm. Nature 355: 730-732.

Rasmussen, E.B. and J.T. Lis. 1993. In vivo transcriptional pausing and cap formation on three Drosophila heat shock genes. Proc. Natl. Acad. Sci. 90: 7923-7927.

Sal ditt-Georgi eff, M., M. Harpold, S. Chen-Kiang, and J. Darnell. 1980. The addition of the $5^{\prime}$ cap structures occurs early in hnrN A synthesis and prematurely terminated molecules are capped. Cell 19: 69-78.

Schul, W., B. Groenhout, K. Koberna, Y. Takagaki, A. Jenny, E.M .M. M anders, I. Raska, R. van Driel, and L. de Jong. 1996. The RN A 3' cleavage factors CstF 64kD and CPSF 100kD are concentrated in nuclear domains closely associated with coiled bodies and newly synthesized RNA. EMBO J.
15: 2883-2892.

Shatkin, A.J. 1976. Capping of eukaryotic mRN As. Cell 9: 645653.

Shuman, S. 1995. Capping enzyme in eukaryotic mRN A synthesis. Prog. Nucleic Acid Res. Mol. Biol. 50: 101-129.

Sisodia, S.S., B. Sollner-Webb, and D. Cleveland. 1987. Specificity of RN A maturation pathways: RN As transcribed by RN A polymerase III are not substrates for splicing or polyadenylation. Mol. Cell Biol. 7: 3602-3612.

Smale, S.T. and R. Tjian. 1985. Transcription of herpes simplex virus tk sequences under the control of wild-type and mutant human RNA polymerase I promoters. Mol. Cell. Biol. 5: 352-362.

Steinmetz, E.J. 1997. Pre-mRNA processing and the CTD of RNA polymerase II: The tail that wags the dog? Cell 89: 491494.

Tani, T. and Y. Oshima. 1991. mRN A-type introns in U 6 small nuclear RNA genes: implications for the catalysis in premRN A splicing. Genes \& Dev. 5: 1022-1031.

Ullman, K.S., M.A. Powers, and D.J. Forbes. 1997. N uclear export receptors: From inportin to exportin. Cell 90: 967-970.

Vincent, M., P. Lauriault, M.-F. Dubois, S. Lavoie, O. Bensaude, and B. Chabot. 1996. The nucleur matrix protein p255 is a highly phosphorylated form of RNA polymerase II largest subunit which associates with spliceosomes. Nucleic Acids Res. 24: 4649-4652.

Visa, N ., A.T. Alzhanova-Ericsson, X. Sun, E. Kiseleva, B. Bjorkroth, T. Wurtz, and B. Daneholt. 1996a. A pre-mRNA binding protein accompanies the RN A from the gene through the nuclear pores and into polysomes. Cell 84: 253-264.

Visa, N., E. Izuarral de, J. Ferreira, B. Daneholt, and I.W. M attaj. 1996b. A nuclear cap-binding complex binds the balbiani ring pre-mRN A cotranscriptionally and accompanies the ribonucleoprotein particle during nuclear export. J. Cell Biol. 133: 5-14.

Wansink, D.G., W. Schul, I. van der Kraan, B. van Steensel, R. van Driel, and L. de Jong. 1993. Fluoresent labeling of nascent RNA reveals transcription by RNA polymerase II in domains scattered throughout the nucleus. J. Cell Biol. 122: 283-293.

Whitelaw, E. and N. Proudfoot. 1986. a-thal assaemia caused by a poly(A) site mutation reveals that transcriptional termination is linked to $3^{\prime}$ end processing in the human $\alpha$ globin gene. EMBO J. 5: 2915-2922.

Yuryev, A., M. Patturajan, Y. Litingtung, R.V. Joshi, C. Gentile, M. Gebara, and J.L. Corden. 1996. The C-terminal domain of the largest subunit of RNA polymerase II interacts with a novel set of serine/arginine proteins. Proc. Natl. Acad. Sci. 93: 6975-6980.

Zachar, Z., J. Kramer, I.P. Mims, and P.M. Bingham. 1993. Evidence for channel ed diffusion of pre-mRN As during nuclear RNA transport in metazoans. J. Cell Biol. 121: 729-742.

Zahler, A.M., K.M. Neugebauer, W.S. Lane, and M.B. Roth. 1993. Distinct functions of SR proteins in alternative premRN A splicing. Science 260: 219-222.

Zehring, W.A., J.M. Lee, J.R. Weeks, R.S. Jokerst, and A.L. Greenleaf. 1988. The C-terminal repeat domain of RNA polymerase II largest subunit is essential in vivo but is not required for accurate transcription initiation in vitro. Proc. Natl. Acad. Sci. 85: 3698-3702.

Zeng, C., E. Kim, S.L. Warren, and S.M. Berget. 1997. Dynamic relocation of transcription and splicing factors dependent upon transcriptional activity. EMBO J. 16: 1401-1412.

Zhang, G., K.L. Taneja, R.H. Singer, and M.R. Green. 1994. Localization of pre-mRNA splicing in mammalian nuclei. Nature 372: 809-812. 


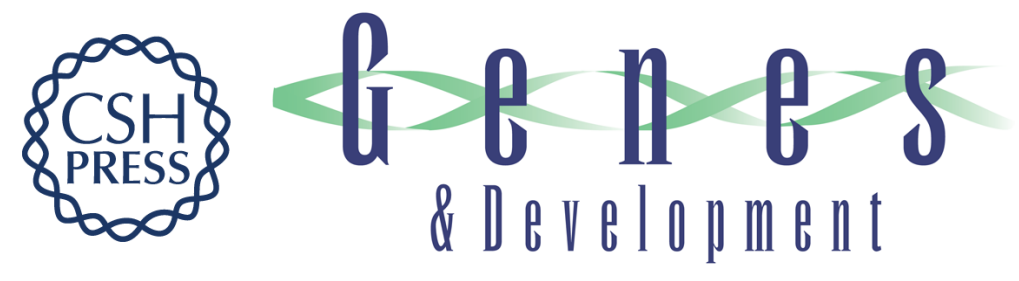

\section{Transcription units as RNA processing units}

Karla M. Neugebauer and Mark B. Roth

Genes Dev. 1997, 11:

Access the most recent version at doi:10.1101/gad.11.24.3279

References This article cites 76 articles, 46 of which can be accessed free at: http://genesdev.cshlp.org/content/11/24/3279.full.html\#ref-list-1

License

Email Alerting Receive free email alerts when new articles cite this article - sign up in the box at the top Service right corner of the article or click here.

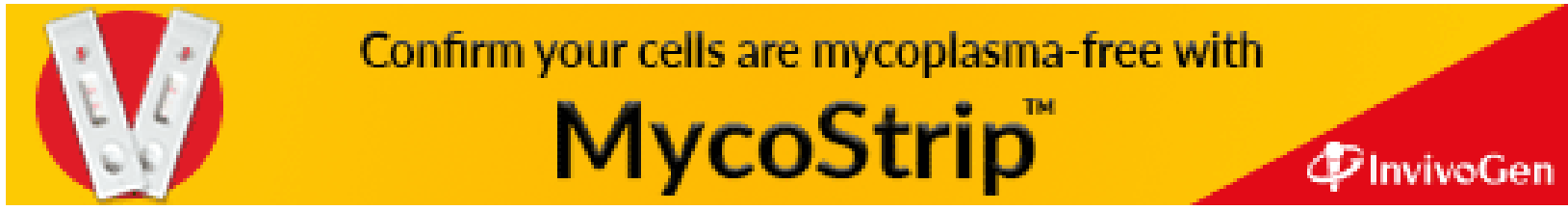

